\title{
Synchrotron-Based Experimental
} Investigations and Numerical Modeling of the Kinetics of Phase Transformations in the Heat Affected Zone of Welds

J.W. Elmer, J. Wong, T. DebRoy, Z. Yang, S. Sista, S.A. David, S. Babu

\section{May 4, 2000}

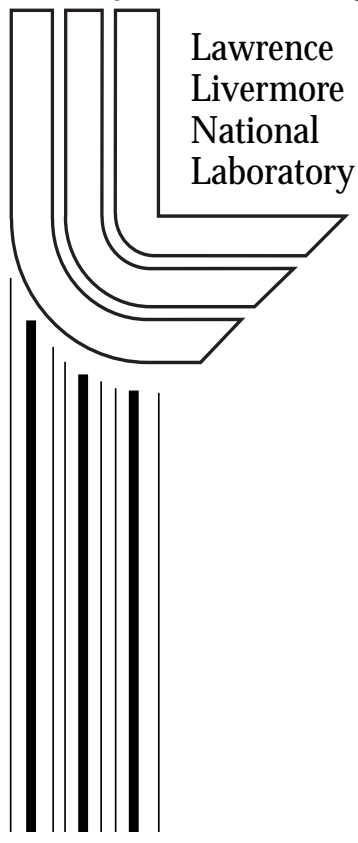




\section{DISCLAIMER}

This document was prepared as an account of work sponsored by an agency of the United States Government. Neither the United States Government nor the University of California nor any of their employees, makes any warranty, express or implied, or assumes any legal liability or responsibility for the accuracy, completeness, or usefulness of any information, apparatus, product, or process disclosed, or represents that its use would not infringe privately owned rights. Reference herein to any specific commercial product, process, or service by trade name, trademark, manufacturer, or otherwise, does not necessarily constitute or imply its endorsement, recommendation, or favoring by the United States Government or the University of California. The views and opinions of authors expressed herein do not necessarily state or reflect those of the United States Government or the University of California, and shall not be used for advertising or product endorsement purposes.

This work was performed under the auspices of the U. S. Department of Energy by the University of California, Lawrence Livermore National Laboratory under Contract No. W-7405-Eng-48.

This report has been reproduced directly from the best available copy.

Available to DOE and DOE contractors from the

Office of Scientific and Technical Information

P.O. Box 62, Oak Ridge, TN 37831

Prices available from (423) 576-8401

http://apollo.osti.gov/bridge/

Available to the public from the National Technical Information Service

U.S. Department of Commerce 5285 Port Royal Rd., Springfield, VA 22161

http://www.ntis.gov/

OR

Lawrence Livermore National Laboratory Technical Information Department's Digital Library http://www.llnl.gov/tid/Library.html 


\title{
Synchrotron-based experimental investigations and numerical modeling of the kinetics of phase transformations in the heat affected zone of welds
}

\author{
J. W. Elmer and J. Wong: Lawrence Livermore National Laboratory \\ T. DebRoy, Z. Yang and S. Sista: The Pennsylvania State University \\ S. A. David and S. Babu: Oak Ridge National Laboratory
}

\section{Motivation}

Spatially Resolved X-Ray Diffraction (SRXRD) and Time Resolved X-Ray Diffraction (TRXRD) methods are being developed at LLNL for in-situ investigations of phase transformations in the heat-affected zone (HAZ) of welds. In this region of the weld, severe temperature gradients, high peak temperatures and rapid thermal fluctuations occur as the heat source passes through the material. These non-isothermal temperature fluctuations produce HAZ microstructures that cannot be predicted by conventional methods. The unique synchrotronbased experiments being developed here will enable the determination of phase transformation kinetics under true non-isothermal welding conditions, and can be used to aid in the development of models to predict HAZ microstructural evolution under a wide range of welding conditions. Commercially pure titanium, stainless steel alloys and plain carbon steels are currently under investigation.

\section{Accomplishments}

SRXRD experiments on AISI type 304 stainless steel gas tungsten arc (GTA) welds were recently completed. These in-situ experiments were conducted using a high-flux x-ray beam at Stanford Synchrotron Radiation Laboratory (SSRL) to investigate the solidifying weld crater with time-resolved experiments (50 $\mathrm{ms}$ resolution), and the HAZ with spatially resolved experiments (260 $\mu \mathrm{m}$ resolution). Both stationary (spot) welds and moving welds were examined. Results of the stationary weld experiments showed, for the first time, that solidification occurs directly to the delta ferrite phase. After solidification to $\delta$, the $\delta \rightarrow \gamma$ phase transformation in this stainless steel alloy was observed as the weld cooled to room temperature. New SRXRD experiments were performed on AISI 1005 carbon-manganese steel. In this alloy system, long-range diffusion of interstitial carbon plays a major role in the phase transformation kinetics. These results are being analyzed, and will be used to map the regions of the ferrite, austenite and delta phases of iron in the weld HAZ. TRXRD studies are being performed on a flux cored arc welding electrode used for welding low carbon structural steels through our collaboration with Oak Ridge National Laboratory. The TRXRD measurements performed on the two steel alloys are further being studied to determine if in-situ temperature measurements can be made using the 2- $\theta$ shift in the diffraction peaks of the ferrite phase during heating and cooling.

The SRXRD-based phase transformation map for grade 2 titanium was analyzed with the aid of a transient, three-dimensional, turbulent heat transfer and fluid flow model and modified JohnsonMehl-Avrami formalism. This work was performed in collaboration with the Penn State University, and the results successfully predicted the region of $\alpha+\beta$ coexistence around the titanium weld pool. The model was used to compare different rate controlling steps for the $\alpha \rightarrow \beta$ 
transformation and was used to predict the region where the complete transformation to the $\beta$ phase had occurred. Real-time evolution of the grain structure in the single-phase $\beta$ region of titanium was also modeled (see Figure 1) using a three-dimensional Monte Carlo technique coupled to the heat transfer and fluid flow model. This code was specifically developed to account for the steep HAZ thermal gradients that exist around the weld pool.

\section{Significance}

Unique synchrotron-based SRXRD and TRXRD experimental techniques being developed at LLNL can be used for real time observations of phase transformations under the steep thermal gradients produced during welding. These techniques provide the only known direct observations of the phases present during welding and can be used to measure phase transformation kinetics during heating and cooling of welds. Numerical weld modeling of the synchrotron-based experimental data allows predictions of weld behavior to be made over a wider range of welding parameters than is experimentally examined, and can be used to help identify the most likely phase transformation mechanisms responsible for microstructural evolution in welds. The insight developed in this research could not be achieved without concomitant modeling and experiments

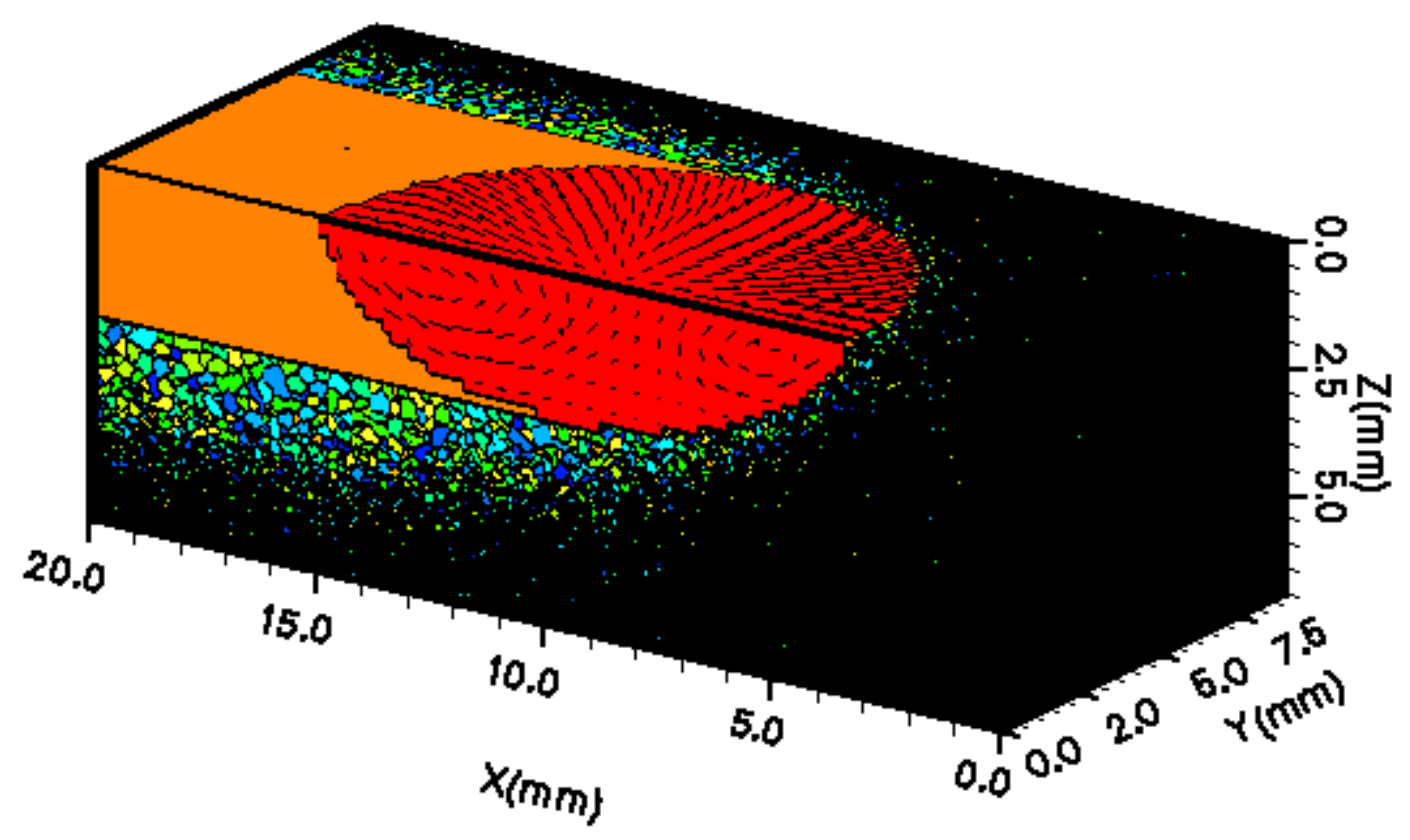

Figure 1: Real time 3-dimensional simulation of grain size evolution in the HAZ of a 1.9 $\mathrm{kW}$ GTA weld moving at $1.1 \mathrm{~mm} / \mathrm{s}$ in titanium. Fluid flow vectors are shown in the liquid weld pool (red) for the weld that is moving from left to the right. (Z. Yang, J. W. Elmer, Joe Wong, and T. DebRoy, Welding Journal, 79(4), p. 97s-112s, 2000). 
$\underline{\text { Recent Publications }}$

1. Z. Yang, J. W. Elmer, Joe Wong, and T. DebRoy, "Evolution of Titanium Arc Weldment Macro- and Microstructures - Modeling and Real Time Mapping of Phases," Welding Journal, 79(4), p. 97s-112s, 2000.

2. Z. Yang, S. Sista, J. W. Elmer, and T. DebRoy,"Three Dimensional Monte Carlo Simulation of Grain Growth During GTA Welding of Titanium," submitted to Acta Metall. Mater., March, 2000.

3. Joe Wong, P. A. Waide, J. W. Elmer and A. C. Thompson, "Spatially Resolved Diffraction using a Soller Collimator-Imaging Plate Assembly," Nucl. Instrum. Meth. $A,(1999)$ in press.

4. J. W. Elmer, Joe Wong and Thorsten Ressler, "In-situ observations of phase transformations during solidification and cooling of austenitic stainless steel welds using time-resolved x-ray diffraction," submitted to Scripta Materialia, October, 1999.

5. Joe Wong, "Chemical Dynamics and Phase Transformation in High Temperture Processess using TRXRD and SRXRD”, invited chapter in Chemical Applications of Synchrotron Radiation, ed. T.K. Sham, World Scientific Publishing Co., 1999, in press.

6. J. W. Elmer, Joe Wong and Thorsten Ressler, "Direct observation of phase transformations in austenitic stainless steel welds using in-situ spatially resolved and time resolved x-ray diffraction," The Second International Symposium on the Joining of Advanced Materials ASM Materials Solutions '99, Cincinnati, Ohio, November 14, 1999, in press.

7. Z. Yang, J. W. Elmer, Joe Wong, and T. DebRoy, "A Combined Modeling and Experimental Study of Microstrutural Evolution in Titanium Arc Welds," The Second International Symposium on the Joining of Advanced Materials ASM Materials Solutions '99, Cincinnati, Ohio, November 1-4, 1999, in press. 